\title{
Afetos, cultura e mediação: especificidades do desenvolvimento na criança de zero a três anos
}

\section{Cláudia Aparecida Valderramas Gomes*}

\section{Resumo}

Ao anunciar a materialidade dos processos psicológicos humanos, a psicologia histórico-cultural destaca que a cultura é a matéria-prima do desenvolvimento, ou seja, é por meio da inserção da criança, desde o seu nascimento, no universo da linguagem, dos objetos e da história dos homens que a mesma constitui sua condição humana. Esse artigo tem como objetivo apresentar algumas particularidades do desenvolvimento da criança nos primeiros três anos de vida destacando os processos afetivos e a interposição da cultura nesse processo. Utilizando como aporte teórico principal a psicologia de Vigotski e, de maneira especial, o conteúdo referido nas Obras Escolhidas, tomo IV, o artigo contribui para pensar a educação das crianças ainda na primeira infância indicando o papel que os elementos mediadores, em especial os educadores, desempenham nesse processo como forma de expressar outra atitude frente à aprendizagem e ao desenvolvimento.

Palavras-chave: Educação. Psicologia da criança. Teoria sócio-histórico-cultural.

* Doutora em Educação pela Universidade Estadual Paulista Júlio de Mesquita Filho (UNESP). Professora no Curso de Psicologia e no Programa de Pós-graduação em Psicologia da Universidade Estadual Paulista Júlio de Mesquita Filho, campus Assis. 


\section{Introdução}

Discorrer sobre o desenvolvimento da criança na perspectiva histórico-cultural implica antes de qualquer coisa situar, nesse campo teórico, como os estudiosos trataram tal assunto. A constituição dessa psicologia deu-se no início do século XX a partir dos estudos de Lev Semiónovich Vigotski ${ }^{1}$ (1896-1934), Alexander Romanovich Luria (1902-1977) e Aleksei Nikolaevich Leontiev (1903-1979), os quais se uniram na afirmação da materialidade dos processos psicológicos humanos. Para tanto, buscaram no materialismo histórico e dialético os fundamentos teórico-filosóficos e metodológicos que embasaram suas formulaçôes acerca do desenvolvimento humano, tendo em vista romper com os enfoques idealistas e materialistas mecanicistas vigentes na psicologia.

Vygotski (1991) destacava a importância de um método que desse conta da complexidade do que entendia ser o objeto da psicologia: os processos e funçóes psicológicas tipicamente humanas. Sendo assim, postulava a necessidade de uma teoria que fizesse a mediação entre o método materialista histórico e os fenômenos psíquicos, tendo em vista explicar a natureza social do psiquismo e a dialética do seu desenvolvimento.

Esses autores pretendiam superar ideias, tais como a desvinculação entre o desenvolvimento psicológico e as bases materiais concretas, isto é, sociais e históricas. Além disso, procuravam romper com a tendência a identificar o psiquismo com a simples maturação de estruturas orgânicas, tanto quanto com a ideia da formação das funçôes psíquicas complexas como consequência natural do desenvolvimento de estruturas simples.

Os pressupostos da materialidade e da historicidade estáo presentes no conceito de desenvolvimento humano. Entretanto, para pensá-lo como histórico e cultural fazse necessário fundamentar sua constituição tendo em vista o uso de signos $\mathrm{e}$ instrumentos, já que estes são processos intrincados a um conceito mais amplo, o de atividade mediadora, e o princípio da mediação na teoria vigotskiana sustenta o conceito de desenvolvimento cultural.

Assim, quando se trata de explicar a constituição do psiquismo na ontogênese, não há como fazê-lo senão recorrendo à cultura, cerne de onde tudo principia, já que deriva dela a natureza essencial dos elementos mediadores constitutivos do desenvolvimento psicológico da criança. Contudo, como sugere Sirgado (2000, p.47, grifos do autor), é preciso advertir que tanto "a natureza do social como a maneira como ele se torna constitutivo de um ser cultural' é, sem dúvida alguma, um aspecto muito importante na obra de Vigotski. 
Para esse autor, Vigotski (1997, p. 106 apud SIGARDO, 2000, p.54) define a cultura como "um produto, ao mesmo tempo, da vida social e da atividade social do homem", ou seja, na primeira parte da afirmação, Vigotski reforça que a cultura deve ser entendida como prática social resultante das relaçóes sociais que caracterizam uma dada sociedade, e na segunda parte, a mesma deve ser entendida como produto do trabalho social na acepçáo marxiana do termo. Portanto, em Vigotski "a cultura é a totalidade das produções humanas (técnicas, artísticas, científicas, tradiçōes, instituiçōes sociais e práticas sociais)", ou seja, "a natureza da cultura está relacionada com o caráter duplamente instrumental, técnico e simbólico, da atividade humana” (SIRGADO, 2000, p. 54).

Diante da interconexão conceitual que os termos - social e cultural - assumem na explicação vigotskiana sobre os processos psicológicos humanos, reiteramos a necessidade de romper com o pressuposto de estágios regulares e descritivos do desenvolvimento, tratando-o como um fato universal, já que não se presume o mesmo padráo de comportamento para toda e qualquer criança. Inversamente, a perspectiva histórico-cultural concebe o desenvolvimento do sujeito como a síntese que a sua história de apropriaçóes e de experiências sócio-culturais foi capaz de lhe proporcionar.

Por isso, ao comentarmos o desenvolvimento da criança entre zero e três anos de idade, apresentaremos algumas propriedades mais gerais desse período marcado, sobretudo, pelas condiçóes concretas e objetivas de vida e de educação. Para isso, nos apoiaremos nas Obras Escolhidas de Vygotski (1996) - volume IV, trabalho no qual ele propóe o estudo das idades buscando o conteúdo das leis gerais que as regulam, tanto nos período estáveis como críticos.

Segundo Vygotski (1996), os períodos considerados críticos se intercalam entre os estáveis e representam pontos decisivos, de transformação qualitativa do desenvolvimento da criança ressaltando, ainda, o caráter brusco e descontínuo das mudanças suscitadas pelas aprendizagens, ou seja, o desenvolvimento não apresenta uma linearidade, nem, tampouco, uma regularidade, mas tem um caráter imprevisível.

Desse modo, o presente texto pretende conhecer algumas ocorrências que provocam transformaçôes na vida da criança ao longo dos três primeiros anos, potencializando seu desenvolvimento. Isso pressupóe falarmos de como se dá a interposição dos processos afetivos, bem como explicar como a cultura se pôe nesse processo. 


\section{Referências sobre o desenvolvimento da criança no primeiro ano de vida}

Vygotski (1996) destaca que para se conhecer a estrutura ${ }^{2}$ e a dinâmica de cada idade, a primeira condição é perceber que há uma relação entre a personalidade da criança e seu meio social.

No nascimento a criança se separa da mãe fisicamente, mas não biologicamente. O recém-nascido tem uma existência marcada pelos processos biológicos da alimentação, sono e vigília, além de movimentos reflexos. Segundo o autor, nesse momento já se pode falar em vida psíquica, porque a criança já se encontra inserida num contexto humano e social. Ele refere, ainda, que o recém-nascido possui rudimentos da vida psíquica associada ao funcionamento dos centros mais primitivos do cérebro subcorticais - e, como o cérebro está ainda imaturo, os processos instintivos e os afetos mais simples ficam dependentes dessas instâncias menos desenvolvidas do sistema nervoso. $\mathrm{O}$ autor afirma que:

[...] o estado do sistema nervoso do recém-nascido não exclui em absoluto a possibilidade de que tenha vida psíquica; obriganos a supor, melhor, a existência de rudimentos psíquicos, ainda que totalmente distintos da psique desenvolvida do adulto e das crianças maiores [...]. Tudo o que podemos admitir com algum fundamento é a existência de estados de consciência nebulosos, confusos, nos quais o sensitivo e o emocional se acham fundidos a tal ponto que caberia qualificá-los de estados sensitivos emocionais ou estados de sensaçóes marcadas emocionalmente. (VYGOTSKI, 1996 p. 281, tradução e grifos nossos).

Nesta etapa da vida, tudo aquilo que o bebê percebe do meio está unido com o afeto; para ele, a percepçáo do que é agradável ou ameaçador aparece muito antes do que os elementos físicos e sociais da realidade exterior, o que sugere uma fusão de atração, afeto e sensação. É uma reação muito peculiar a um todo complexo de matiz emocional, que impede sua percepção diferenciada dos elementos isolados da situação (VYGOTSKI, 1996).

Do ponto de vista social, no período pós-natal, que Vygotski (1996) limita a mais ou menos três semanas, evidencia-se uma passividade total da conduta do bebê. Ao final do primeiro e início do segundo mês aparece a resposta de sorriso da criança, ou seja, a primeira reação específica à voz humana; esse é o indicativo que marca uma nova formação central no desenvolvimento social da sua personalidade. 
O desenvolvimento do comportamento social do bebê ao segundo mês de vida já aponta para impressóes e reaçóes especificamente sociais, ele responde sorrindo ao ouvir a voz humana, deixa de gritar se alguém se aproxima dele e se volta até a pessoa que fala, demonstra atenção e reage quando dele se afastam. A partir de então, já é possível falar de impressóes e reaçóes sociais do bebê e isso significa um marco distintivo de uma etapa de passividade e outra de início de resposta ativa por parte da criança. Aos três meses já se manifesta disposto à comunicação, mas o desejo efetivo de se comunicar só deverá aparecer no segundo semestre de vida.

Em Spitz (1993) encontramos algumas explicaçôes sobre a complexidade do processo de aquisição da fala. Segundo ele, "a vocalização do bebê, que a princípio serve para descarregar tensão passa por modificaçôes progressivas até tornar-se um jogo em que a criança repete e imita sons que ela mesma produziu" (SPITZ, 1993, p. 73). No início o bebê não faz distinção entre os sons vindos do ambiente e aqueles produzidos por ele mesmo, apesar disso:

Em certo momento deste processo, cronologicamente em torno do terceiro mês de vida o bebê se torna consciente de que pode ouvir os sons que ele mesmo produz e que estes sons são diferentes daqueles que vêm do ambiente que o cerca. Ele não pode influir nos sons do ambiente, mas tem o poder de entreter-se, produzindo seus próprios ruídos ou parando de produzi-los. (SPITZ, 1993, p. 73).

A vocalização, como tal, ainda conserva sua qualidade de descarga, de redução de tensão, de prazer. Porém, um novo fazer entrou em sua vida: o domínio da produção de algo que pode ser recebido como estimulação em outro setor do aparelho sensorial. Após o terceiro mês de vida, podemos observar as experiências do bebê quanto a essa habilidade, através de monólogos balbuciantes (SPITZ, 1993) em que o bebê produz sons, geralmente de variedade rítmica, repetitiva, linguais e labiais. Ele é capaz de ouvilos cuidadosamente e repetir inúmeras vezes, criando seu próprio eco, a primeira imitação acústica. De acordo com Spitz (1993), seis meses mais tarde ele utilizará esta experiência ao imitar os sons que ouve do adulto que cuida dele.

Essa particularidade no processo de aquisição da linguagem oral tem significativas diferenças quando comparamos o bebê ouvinte ao surdo. A criança ouvinte quando balbucia, produz um feedback auditivo ao ouvir sua própria voz, o que gera prazer e, em geral, faz com que ela continue reproduzindo esses sons, ao contrário, a criança surda que náo ouve seu próprio balbucio tende a diminuir a frequência de emissóes vocais até que ele desaparece, ou seja, tal processo náo se complexifica a caminho do pleno desenvolvimento da linguagem verbal. 
Nos primeiros meses de vida, mesmo sendo incapaz de ouvir sua própria voz, a criança deficiente auditiva chora e vocaliza da mesma maneira que uma criança ouvinte. Porém, à medida que envelhece, ocorre uma restrição em seu repertório relacionado à qualidade e à quantidade de sons, podendo não desenvolver o balbucio silábico. Já no final do primeiro ano, sua vocalização reduz-se ao que ela pode sentir, ou seja, sons guturais ou gritos agudos, semelhantes àqueles produzidos por bebês de um mês de vida. (PRADO, 2007, p. 404-405).

Entre o sexto e o nono mês de vida tem início a manipulação de objetos que é a etapa prévia ao uso de ferramentas com um fim prático ou instrumental. Segundo Vygotski (1996), na criança de sete meses já é possível constatar indícios de uma atividade objetal e, por volta do décimo até o décimo segundo mês, produzem novas formas de comportamento, mais complexas, trata-se do início da utilização de ferramentas. São as primeiras manifestaçôes do intelecto prático ou pensamento instrumental, a criança desenvolve uma atividade orientada a um fim, um pensamento visual-direto, ativo, que ocorre antes da aparição da linguagem oral.

Vygotski (1996) destaca que as percepçóes do recém-nascido e do bebê começam a se desenvolver a partir de situaçóes globais, complexas, e tem um caráter não dissociado do contexto no qual acontecem. Daí que suas explicaçóes sobre o nexo que une os processos sensoriais e motores se voltam para uma estrutura geral interna atribuída de sentido, que é o impulso, a necessidade, ou falando de forma ampla, o afeto: "A percepção e a ação estão unidas pelo afeto" (VYGOTSKI, 1996, p. 298, tradução nossa).

Nas primeiras relaçóes da criança com os objetos predomina a experiência afetivo-emocional, trata-se de uma percepção imediata que acontece por meio do suporte dos órgãos sensoriais; é o aparelho sensorial que medeia e organiza essa vivência. Essa relação sensível e impulsiva alheia à vontade e ao controle da própria conduta, acontece na ausência da linguagem e da função reguladora que a mesma confere ao pensamento.

Decorre desse fato a lei que ele postula sobre a vida psíquica do bebê: "um sistema de consciência instintiva que se desenvolve pela influência dominante dos afetos e atraçóes" (VYGOTSKI, 1996, p. 298, tradução nossa). Vigotski faz uma consideração importante ao colocar o afeto na dinâmica de formação da consciência do bebê haja vista que muitos investigadores, que defendem a importância dos afetos relacionados preferencialmente com o mecanismo subcortical da consciência e o comportamento do bebê, deduzem que os afetos, em geral, são próprios de uma psique primitiva correspondente a um estágio inferior do desenvolvimento. 
Ao refutá-los, Vygotski (1996) afirma que o afeto, ao participar no processo de desenvolvimento psíquico como fator essencial, percorre um caminho complexo que se modifica em cada nova etapa de formação da personalidade e toma parte na estrutura da nova consciência, própria de cada idade. Para o autor, o afeto inicial do recém-nascido circunscreve sua vida psíquica aos limites do sono, alimentação e choro e, portanto, no início adota a forma de um interesse receptivo pelo mundo exterior que vai aos poucos se transformando e, em seguida, passa a se constituir em um interesse ativo pelo entorno.

Os processos afetivos, ligados aos instintos nas primeiras etapas do primeiro ano, são processos psíquicos que se conectam a cada uma das demais funçôes psicológicas na estrutura da consciência. Com o desenvolvimento a caminho da integração funcional em que a linguagem passará a se conectar ao pensamento, a percepção à ação, os afetos se póem no centro de um processo que, além de sofrer as determinações das demais funções psíquicas, constituem força motivacional que impulsiona e, ao mesmo tempo, são atravessados pelas constantes transformaçóes ocorridas na estrutura da personalidade.

As necessidades vão se transformando sob a exigência de novas demandas externas e internas ao sujeito, isso implica numa transformação permanente do afeto, já que este se caracteriza pelo aumento ou diminuiçăo da potência de agir e de pensar do sujeito na relaçáo que o mesmo mantém com o objeto que atende a uma dada necessidade (GOMES, 2008).

No que tange às formas de relação social presentes nesse momento da vida, Vygotski (1996 p. 304, tradução nossa) ressalta a importância do adulto na estruturação psíquica da criança no primeiro ano:

A atividade da criança na presença do adulto se realiza sempre através dele. Por este motivo, a outra pessoa é para o bebê o centro psicológico de toda a situação. O sentido de cada situaçáo está determinado para o bebê por esse centro principalmente, quer dizer, por seu conteúdo social, ou melhor, pela relação da criança com o mundo. A criança é uma magnitude dependente e derivada de suas relaçóes diretas e concretas com o adulto.

Assim, é possível dizer que o adulto assume a posição de mediador principal nas relaçôes da criança com a realidade social. O intercâmbio adulto-bebê é mediado pelos objetos, da mesma forma que a sua própria relação com os objetos requer a mediação dos adultos. É este quem apresenta o objeto para a criança, mostra seu funcionamento e 
suas propriedades e é assim que a cultura vai sendo apresentada à criança suscitando nela novas necessidades.

Para o bebê nessa idade o distanciamento visual do objeto equivale a seu distanciamento psíquico, ou seja, conforme a distância existente entre o bebê e o objeto, a atração afetiva para com o mesmo se debilita. Portanto, quanto mais próximo do objeto, mais intenso é o afeto e o seu afastamento visual em relação àquele equivale à separaçáo psíquica e a consequente desaparição do impulso afetivo que antes o atraia. No entanto, quando o objeto se distancia e diminui a atração afetiva, é possível suscitar de novo seu interesse, basta que um adulto se aproxime.

A presença mediadora do adulto é tão importante, nessa idade, que o impulso afetivo para com o objeto que está distante depende se este está no mesmo campo no qual a criança percebe o adulto. Nesse caso, a força impulsionadora afetiva será a mesma de quando o objeto está próximo a ela e alcançável por seu próprio esforço.

A situaçâo social do desenvolvimento ${ }^{3}$ no primeiro ano sinaliza que existe uma acentuada incapacidade biológica que determina uma dependência entre o bebê e os adultos. O adulto é a principal via de atividade do bebê e os contatos da criança com a realidade é socialmente mediado, do que se conclui que a presença do adulto perpassa, necessariamente, todas as formas de relação da criança com essa realidade. Mas é preciso destacar que a criança não dispóe, ainda, dos meios fundamentais da comunicação social na forma humana da linguagem, consequentemente assistimos a uma contradiçáo que vai marcar a virada do desenvolvimento do bebê ao final do primeiro ano de vida: suas máximas condiçóes de sociabilidade, que compreende uma diversidade de relaçóes sociais da criança, do desdobramento de sua atividade, aperfeiçoamento de seus movimentos e intensa maturaçáo de algumas partes do seu cérebro incompatível com as mínimas possibilidades de estabelecer comunicação direta com os adultos por meio da linguagem oral.

Esse aspecto vai deflagrar aquilo que Vygotski (1996) nomeou como a crise do primeiro ano, período de viragem quando ao término do primeiro ano a criança passa à primeira infância. Segundo o autor, os avanços que a criança conquista na idade crítica tem caráter transitório e não perdura na idade seguinte. Diferentemente, tudo aquilo que é alcançado no período estável permanece. Em consonância com a lei dialética do desenvolvimento, as conquistas das idades críticas não desaparecem, tão somente se convertem em formaçóes mais complexas cumprindo uma determinada funçáo naquela etapa do processo. 


\section{Aspectos do desenvolvimento da criança entre um e três anos}

Uma característica que acompanhará a crise do primeiro ano é a aparição da linguagem autônoma infantil. A criança a vivencia como um marcador de passagem à primeira infância; seu começo e final marcam o início e o final da crise. Nesse tipo de linguagem o significado das palavras depende sempre da situação presente e, por conseguinte, no estágio da linguagem autônoma não existe ainda a possibilidade de pensamento verbal desvinculado da situaçáo visual-direta; táo logo a palavra se separa do contexto imediato perde seu significado.

A linguagem autônoma infantil é uma etapa peculiar no desenvolvimento do pensamento, um tipo de pensamento ainda subordinado à percepção, logo esse tipo de linguagem transmite o conteúdo afetivo das impressôes percebidas; ainda é uma percepção ligada ao afeto: "A palavra pode ser utilizada na comunicação somente quando o objeto está à vista. Se o objeto está visível, a palavra se faz compreensível" (VYGOTSKI, 1996, p. 328, tradução nossa).

Com a superação dessa fase e a crescente apropriação da linguagem, novas relaçôes se estabelecem entre a criança e a realidade social. A partir de agora a palavra carrega um significado, e esse é que fará a mediação entre a criança, os objetos e as pessoas, contudo, é importante destacar que tais significados são construídos de forma gradual, não são apropriados integralmente e de uma só vez. Em Vigotski (apud MELLO, 2010, p. 732) temos que:

Tal concepção está ligada ao que constitui o significado de nossa palavra. Vocês sabem, é claro, que nos comunicamos com as pessoas em torno de nós, principalmente, com a ajuda da fala. Esse é um dos recursos fundamentais, com a ajuda do qual a criança possui contato psíquico com as pessoas ao seu redor. A pesquisa da fala mostrou que o significado das palavras para as crianças não coincide com nosso significado da palavra, ou seja, o significado das palavras para crianças em diferentes faixas etárias possui uma construção diferente.

No que tange às relaçôes da criança - na primeira infância - em presença os objetos exteriores, Vygotski (1996) assinala que agora o social e o objetal na situaçáo presente estáo bastante diferenciados, por isso para ela o trânsito entre o objeto e o adulto se altera, ou seja, ela recorre ao adulto na impossibilidade de alcançar seu objetivo, o que para o bebê era impossível. 
Um dos traços característicos do comportamento da criança em sua relação com a realidade é a dependência da situação presente. Por causa dessa dependência do campo visual-direto o que ela vê a influencia muito e os objetos adquirem um caráter imperativo, um caráter de "afeto coercitivo": "É como se de cada objeto emanasse um afeto de atração ou repulsão que é o motivo que estimula a criança" (VYGOTSKI, 1996, p. 342, tradução nossa).

Ele reforça que o que condiciona essa conduta é a unidade das funçóes sensoriais e motoras - "a criança deseja tocar tudo o que vê" (VYGOTSKI, 1996, p. 343, tradução nossa), sua atividade está circunscrita àquilo que lhe sugerem os objetos circundantes. A primeira percepção infantil é a afetiva, ou seja, a percepção e o sentimento formam uma unidade indissolúvel. O que motiva a criança é deflagrado pelos objetos, o que mudou foi a necessidade, que é o substrato do afeto. A necessidade agora é de outra natureza, posto que são os objetos que ocupam o lugar principal na atividade da criança.

À medida que cresce a criança vai se apropriando dos objetos e instrumentos pela mediação dos adultos, já que são eles que lhes apresentam a função social dos mesmos. Vygotski (1996) assinala que a principal nova formaçáo da primeira infância está vinculada à linguagem, graças a qual a criança estabelece distintas relaçóes com o meio social.

Nessa idade se forma na criança uma visão estável do mundo, ela demonstra capacidade para ordenar os objetos e diferenciá-los graças à linguagem, daí as perguntas sobre o significado daquilo que vê. No entanto, ainda inexiste a separaçáo objetiva entre palavras e objetos, as crianças antes dos três anos não admitem mudar os nomes das coisas, parece difícil para ela aceitar a desvinculaçáo entre as palavras e os objetos concretos que elas representam; a palavra se revela como a qualificação do próprio objeto. Como exemplo, temos a expressão de uma criança de três anos na frase: "o sofá da minha casa se chama poltrona".

O domínio da linguagem leva a uma nova configuraçấo de toda a estrutura da consciência. Nessa idade a mudança no sistema de inter-relações entre as funções se acha diretamente vinculado com o significado das palavras e este significado começa a mediar os processos psíquicos.

Todas as transformaçôes nessa etapa do desenvolvimento que culminaram com a conquista da locomoçáo, da linguagem oral, o ganho com a diferenciação da percepção que possibilitou a desvinculaçáo de si mesma em relação às demais pessoas e objetos na situaçáo, não foram suficientes para garantir sua independência psicológica daqueles que a cercam e isso vai marcar um novo momento no seu desenvolvimento. Nesse processo já é perceptível a ocorrência de mudanças na esfera afetiva e volitiva, haja vista a crescente independência e atividade da criança, suas relaçôes com as pessoas já 
não são as mesmas de antes, o que Vygotski (1996) denomina como a crise dos três anos assinalando uma nova etapa de emancipação.

Esse momento, constitutivo da idade crítica, vai se traduzir por alguns sintomas tais como o negativismo, a insistência, a rebeldia ou insubordinação. Tais sinais demonstram que, a partir de agora, o que motiva a criança não é propriamente $o$ conteúdo da situação, mas as relaçôes que mantém com as outras pessoas. $\mathrm{O}$ que caracteriza esse momento é, fundamentalmente, o fato de a criança conseguir se desprender da situaçáo imediata; o motivo difere da situação.

É preciso enfatizar que essas crises não são internas e naturais, típicas da idade, mas sáo derivadas das novas conquistas da criança e da incompreensáo dos adultos que, pelo desconhecimento do processo de desenvolvimento, assumem uma atitude imediata e não-refletida frente ao comportamento infantil. Desse modo, as crises não precisam necessariamente acontecer, mas as rupturas da criança e os saltos qualitativos do seu desenvolvimento são inevitáveis.

\section{Algumas considerações para pensar a educação na pequena infância à luz da psicologia histórico-cultural}

Se considerarmos que a psicologia histórico-cultural pode ser um dos fundamentos de uma pedagogia (DUARTE, 2013), as particularidades do desenvolvimento entre zero e três anos, acima discutidas, certamente contribuirão para pensarmos outra maneira de nos relacionarmos com os bebês e com as crianças pequenas, as quais muitas vezes já se encontram em situação de grupo, nas creches e escolas de educação infantil, aos cuidados de pessoas que não são os familiares diretos.

Conforme a lei genética geral do desenvolvimento cultural formulada por Vygotski (1995 p. 150, tradução e grifo nosso), na qual afirma que "Por detrás de todas as funçôes superiores e suas relaçôes se encontram geneticamente as relaçôes sociais, as autênticas relaçóes humanas", temos de reafirmar a força que exercem os mediadores na estruturação do psiquismo da criança. São os adultos que, participando integralmente da vida do bebê desde o seu nascimento, poderâo intensificar outro modo de se relacionar com os mesmos de tal forma que o bebê seja atraído e estimulado pelos objetos e pessoas ao seu redor ampliando as possibilidades do seu desenvolvimento.

No que diz respeito à aquisição da linguagem, meio efetivo de se apropriar dos signos - reais portadores da cultura humana -, são os adultos que, convivendo com a criança, poderão lhe oferecer a forma ideal (MELLO, 2010) da linguagem verbal utilizada pelas pessoas no contexto social. Concordamos que a linguagem oral se aprende por via assistemática, na convivência diária, por meio de situaçóes que 
dispensam planejamento e elaboração, mas implica a presença de um interlocutor, falante de uma língua, a oferecer elementos para a criança desde cedo e durante todo o tempo, mesmo naquele momento do seu desenvolvimento em que o bebê se apresenta, ainda, num estágio de passividade frente à realidade exterior.

As experiências com a forma ideal da linguagem oral permitirão ao bebê superar o momento do balbucio e avançar em direção à plena aquisição desse instrumento cultural complexo. Os monólogos que os adultos estabelecem com os bebês durante o tempo que passam cuidando da sua saúde, alimentação e outras atividades diárias podem ser provocativas de uma nova atitude do bebê frente ao mundo.

No que tange a relação da criança com os objetos, produçóes materiais humanas que guardam funções sociais historicamente constituídas, a situação que se coloca aos adultos não é diferente, tendo em vista sua participação, possibilitando a aproximaçáo, o manuseio, a experimentação e a utilização funcional dos mesmos pelas crianças. Cabe dizer que a descriçáo dos caracteres, por meio da linguagem oral, também reforça o quanto conversar com as crianças sobre os objetos anuncia diversas expectativas de conhecimento dos pequenos.

Pensar a aprendizagem como ativadora do desenvolvimento nessa idade significa para o adulto que convive com a criança permitir, tăo logo seja possível, a exploração do espaço físico pelo bebê; disso dependerá o desenvolvimento de sua capacidade para aprimorar o equilíbrio estático e dinâmico, a coordenação viso-motora e, mais tarde, sua capacidade autônoma de execução do andar, do subir, descer, escorregar, rolar e tantos outros diferentes modos de testar sua independência e locomoção. A exploração de diversos objetos, ambientes e situaçóes podem contribuir para que a criança aprenda diferentes sensaçôes, percepçóes e açóes, elementos importantes na constituição das funçôes psíquicas.

Colocar à criança uma diversidade de situaçóes potencializadoras da aprendizagem pode criar condiçôes para que ela aprenda de forma rica e significativa desconstruindo a ideia de que o desenvolvimento do bebê segue um curso evolutivo, previamente programado por disposiçóes biológicas: "Tais características constituemse apenas em condiçôes prévias do desenvolvimento do indivíduo, mas não estabelecem o conteúdo, os limites e a direção desse desenvolvimento" (DUARTE, 1993, p. 42).

O olhar atento de educadores acerca de como se dá a inserção da cultura, representada pelos instrumentos, pelas técnicas, pelas artes, ciência, linguagens e práticas sociais, no curso do desenvolvimento infantil pode provocar novos modos de se relacionar com as crianças pequenas e interferir no movimento do seu desenvolvimento tendo em vista elevá-lo a patamares antes desacreditados. 


\section{Notas}

${ }^{1}$ Optamos, neste texto, pela grafia Vigotski para designação do nome desse autor, porém, no caso de citaçôes e referências bibliográficas que possamos utilizar, respeitaremos as diferentes grafias adotadas nos textos originais.

${ }^{2}$ Entendemos estrutura como uma formação global, uma qualidade da relação dinâmica entre as partes que constitui o todo da personalidade.

${ }^{3}$ Conceito utilizado por Vygotski (1996) para demonstrar que em cada período de idade, a relação que se estabelece entre a criança e a realidade física e social, é totalmente peculiar, específica, única e irrepetível para esta idade.

\section{REFERÊNCIAS}

DUARTE, Newton. A individualidade para-si: contribuição a uma teoria históricosocial da formação do indivíduo. Campinas, SP: Autores Associados, 1993.

DUARTE, Newton. Vigotski e a pedagogia histórico-crítica: a questão do desenvolvimento psíquico. Nuances: estudos sobre educação, Presidente Prudente, SP, v. 24, n. 1, p. 19-29, jan./abr. 2013. Disponível em: <http://revista.fct.unesp.br/index.php/Nuances/article/viewFile/2150/duarte>. Acesso em: 14 mar. 2014.

GOMES, Cláudia Aparecida Valderramas. O afetivo para a psicologia HistóricoCultural: consideraçôes sobre o papel da educação escolar. 2008. 170 f. Tese (Doutorado em Educação) - Universidade Estadual Paulista, Marília, SP, 2008.

MELLO, Suely A. A questão do meio na pedologia e suas implicaçôes pedagógicas. Psicologia USP, São Paulo, v. 21, n. 4, p. 727-739, 2010. Disponível em: <http://www.revistas.usp.br/psicousp/article/view/42024>. Acesso em: 10 mar. 2014.

PRADO, Aline do Carmo. Principais características da produção vocal do deficiente auditivo. Revista CEFAC, São Paulo, v. 9, n. 3, p. 404-410, jul./set. 2007.

Disponível em: <http://www.scielo.br/scielo.php?pid=S151618462007000300014\&script=sci_arttext>. Acesso em: 14 mar. 2014.

SIRGADO, Angel Pino. O social e o cultural na obra de Vigotski. Educação \& Sociedade, Campinas, SP, v. 21, n. 71, p.45-78, jul. 2000. Disponível em: <http://www.scielo.br/pdf/es/v21n71/a03v2171.pdf>. Acesso em: 10 mar. 2014. 
SPITZ, René A. O primeiro ano de vida. Tradução de Erothildes Millan Barros da Rocha. 7. ed. São Paulo: Martins Fontes, 1993.

VYGOTSKI, Lev Semiónovich. Obras Escogidas. Madrid: Visor, 1991. v. 1. VYGOTSKI, Lev Semiónovich. Obras Escogidas. Madrid: Visor, 1995. v. 3.

VYGOTSKI, Lev Semiónovich. Obras Escogidas. Madrid: Visor, 1996. v. 4. 


\section{Affections, culture and media- tion: specificities of develop- ment in children between zero to three years}

\begin{abstract}
Announcing the materiality of human psychological processes, the cultural-historical psychology emphasizes that culture is the source of development, that is, it is through the inclusion of children, from birth, in the universe of language, objects and the history of men that they constitute their human condition. This paper aims to present some particularities of child development in the first three years of life, highlighting the affective processes and the interposition of culture in it. Using as main theoretical contribution Vygotsky's approach to psychology and, mainly, the content of his Selected Works, volume IV, the article aims to contribute to debate early childhood education indicating the role that mediators, especially educators, play in this process as an expression of a new attitude as to learning and development.
\end{abstract}

Keywords: Education. Child psychology. Socio-historical-cultural theory.

\section{Afectos, cultura y mediación: especificidades del desarrollo en los niños desde el naci- miento hasta los tres años}

\section{Resumen}

$\mathrm{Al}$ anunciar la materialidad de los procesos psicológicos humanos, la psicología históricocultural hace hincapié en que la cultura es la materia prima del desarrollo, es decir, es a través de la inclusión de los niños, desde su nacimiento, en el universo del lenguaje, de los objetos y de la historia de los hombres que se constituye la condición humana. Este trabajo tiene como objetivo presentar algunas particularidades del desarrollo del nińo en los primeros tres ańos de vida destacando los procesos afectivos y la interposición de la cultura en este proceso. Utilizando como principal contribución teórica la psicología de Vygotsky, en especial, el contenido de Obras Escogidas tomo IV, el artículo se propone a reflexionar acerca de la educación de los niños aún en los primeros ańos indicando el rol que los elementos mediadores, especialmente los educadores, desempeñan en este proceso como una manera de expresar una nueva actitud hacia el aprendizaje y el desarrollo.

Palabras claves: Educación. Psicología infantil. Teoría socio-histórico-culturales. 


\section{Maria de Lourdes Dionísio}

E-mail: cabegomes@uol.com.br

Recebido em: 22/4/2014

Aprovado em: 26/8/2014 